УДК 674.8

\title{
Increasing the Strength of Carbon Sorbents \\ from the Extracted Larch Bark \\ by Using Additives of Oil Bituminen
}

\author{
Alexey V. Rudkovskiy, \\ Olga Yu. Fetisova and Nikolai V. Chesnokov* \\ Institute of Chemistry and Chemical Technology SB RAS \\ FRC "Krasnoyarsk Science Center SB RAS" \\ 50/24 Akademgorodok, Krasnoyarsk, 660036, Russia
}

Received 13.03.2016, received in revised form 29.04.2016, accepted 04.06.2016

The influence of oil bitumen additives to charcoals, obtained by the pyrolysis of the extracted larch bark on the properties of the active carbons was studied. It was shown that the increase of the amount of bitumen in the charcoal reduces their sorption activity on iodine and rises their abrasion resistance. It was found that after the impregnation of raw charcoal by $10 \%$ solution of bitumen in toluene the sorption activity of activated carbon on iodine reaches $73 \%$ and their abrasion resistance is more than $90 \%$.

Keywords: larch bark, extraction, pyrolysis, activation, carbon sorbents.

DOI: $10.17516 / 1998-2836-2016-9-2-243-251$.

(C) Siberian Federal University. All rights reserved

* Corresponding author E-mail address: cnv@icct.r 


\title{
Повышение прочности углеродных сорбентов
}

\author{
из экстрагированной коры лиственницы \\ путем использования добавок нефтебитума
}

\author{
А.В. Рудковский, \\ О.Ю. Фетисова, Н.В. Чесноков \\ Институт химии и химической технологии СО РАН \\ ФИЦ «Красноярский научный иентр СО РАН» \\ Россия, 660036, Красноярск, Академгородок, 50/24
}

Исследовано влияние нефтебитумных добавок к образиам угля-сыриа, полученным пиролизом экстрагированной коры лиственницы, на свойства активированных углей. Показано, что увеличение количества нефтебитума в углях-сыриах приводит к уменьшению их сорбционной активности по йоду и кувеличению прочности на истирание. Установлено, что при пропитке исходного угля-сыриа раствором 10\%-го нефтебитума в толуоле активность по йоду активированного угля достигает 73 \%, при этом прочность на истирание превымает $90 \%$.

Ключевые слова: кора лиственницы, экстракиия, пиролиз, активаџия, углеродные сорбенты.

\section{Введение}

В результате лесозаготовок образуются отходы окорки стволовой древесины, которые только в Красноярском крае превышают 3 млн т в год. Основная масса этой коры практически не утилизируется. В последнее время активно разрабатываются научные основы технологий комплексной переработки коры [1], в частности коры лиственницы сибирской, в востребованные продукты. Завершающей стадией таких процессов часто является стадия получения углеродных сорбентов из твердых остатков экстракции посредством пиролиза и парогазовой активации [2]. Такие углеродные адсорбенты обладают хорошими адсорбционными характеристиками - активность по йоду достигает 93 \% [3], - превосходящими образцы промышленных активных углей марки БАУ [4], для которых необходимая минимальная активность по йоду составляет 60 \%. Существенным недостатком углеродных адсорбентов из твердого остатка экстракционной переработки коры лиственницы является низкая прочность на истирание. Высокая прочность на истирание - необходимое требование к сорбентам, применяемым в процессах с движущимся слоем адсорбента. В качестве наполнителя таких адсорберов часто выступает активный уголь марки БАУ-А. Поскольку адсорбционная активность по йоду активных углей из коры лиственницы превышает аналогичный показатель угля марки БАУ-А, они могут заменить уголь марки БАУ-А в адсорберах с движущимся слоем при условии сопоставимой прочности на истирание. Один из способов увеличения прочности - предварительная пропитка угля-сырца углеродсодержащими веществами, в частности раствором нефтебитума, с последующим пиролизом и высокотемпературной парогазовой активацией [5]. Парогазовую активацию дробленого сырья, с размером зерна не более 10 мм, удобно проводить в аппаратах 
псевдоожиженного слоя, которые характеризуются высокими коэффициентами тепло- и массообмена, широтой диапазона варьирования параметров процесса.

Цель настоящей работы заключалась в исследовании влияния нефтебитумных добавок на адсорбционные и прочностные характеристики углеродных сорбентов из твердых остатков экстракционной переработки коры лиственницы.

\section{Экспериментальная часть}

Исходным сырьем для экспериментов служила кора лиственницы сибирской, заготовленная в окрестностях Красноярска. Кора вылеживалась в сухом проветриваемом помещении до воздушно-сухого состояния, после чего кора дробилась на дезинтеграторе NOSSEN 8255 с диаметром отверстия сита 6 мм и рассеивалась на фракции.

В работе использовали фракции 2-3 мм, 3-5 мм, 5-6 мм. Отобранные фракции досушивали в сушильном шкафу при температуре $105^{\circ} \mathrm{C}$ до постоянной массы.

Исходный твердый остаток экстракции коры лиственницы получали в лаборатории по методикам, описанным в литературе [6].

Экстракцию проводили в круглодонной колбе объемом 1 л с обратным холодильником. Первоначальная масса навески коры составляла 100 г. Предварительно определяли время экстракции по максимальному выходу целевого компонента.

Кору лиственницы последовательно экстрагировали различными способами, описанными в [7] и [8]. Первый этап - экстракция петролейным эфиром с целью извлечения липидов и смол, гидромодуль 7, продолжительность экстракции 8 ч при температуре кипения. Второй этап экстракции - извлечение дубильных веществ, экстрагент - водный раствор этанола $30 \%$ об., гидромодуль 30, продолжительность 6 ч при температуре $75{ }^{\circ} \mathrm{C}$. Третий этап экстракции - извлечение пищевых красителей, обработка твердого остатка 7\%-ным раствором соляной кислоты в этаноле 95 \% об., гидромодуль 10, время обработки 4 ч при температуре кипения. Четвертый этап экстракции - извлечение пектинов - выполняли по методу, описанному в [8], экстрагент - эквимолярная смесь 0,5\%-го раствора щавелевой кислоты и оксалата аммония, гидромодуль 7, продолжительность обработки 2 ч, температура процесса $80{ }^{\circ} \mathrm{C}$, осаждение пектинов не проводили, поскольку целевым компонентом в данном случае был твердый остаток экстракции.

На каждом этапе экстракции твердый остаток отфильтровывали на бумажном фильтре, промывали дистиллированной водой и сушили до постоянной массы. Массовую долю экстрагированных веществ, \% мас. к абсолютно сухой коре, рассчитывали по уменьшению массы навески коры [9].

Термическую обработку сухого остатка экстракции проводили следующим образом. Вначале получали уголь-сырец из сухого остатка экстракции методом карбонизации. Карбонизацию образцов проводили в цилиндрическом реакторе из нержавеющей стали диаметром 76 мм и высотой 315 мм в электрической печи накаливания. Предварительно образцы коры сушили в сушильном шкафу при температуре $105^{\circ} \mathrm{C}$ до постоянной массы и загружали в реактор, после загрузки образца для удаления воздуха реактор продували аргоном. Скорость нагрева до температуры пиролиза в среднем составляла $10{ }^{\circ} \mathrm{C} /$ мин. Конечная температура пиролиза $500{ }^{\circ} \mathrm{C}$. Время выдержки при конечной температуре 30 мин. По мере нагревания и выделения летучих

$$
-245-
$$


веществ аргон вытеснялся из реактора и пиролиз коры проводился в атмосфере собственных летучих веществ.

Второй этап обработки включал в себя пропитку полученного угля-сырца раствором органического вещества в толуоле и последующую карбонизацию и активацию. В качестве органического вещества для пропитки использовали дорожный нефтебитум марки БНД свойства которого соответствовали ГОСТ 22245-90. Суть подобной обработки состояла в том, чтобы ввести нефтебитум в пористую структуру частицы и, проведя термическую обработку, изменить пористую структуру частицы вследствие пиролиза нефтебитума и осаждения пироуглерода на поверхности пор угля.

Уголь-сырец из коры лиственницы пропитывали раствором нефтебитума в толуоле разной концентрации - 10, 20, 30, 40, 50 \% мас. Предварительные исследования показали, что растворы нефтебитума концентрацией 40, 50 \% мас. имеют большую вязкость и не проникают внутрь угольных частиц, поэтому в дальнейшем использовали образцы, пропитанные раствором нефтебитума в толуоле следующих концентраций: 10, 20, 30 \% мас. Полная пропитка (т. е. прекращение увеличения массы навески) угля-сырца фракции 5-6 мм при комнатной температуре происходит в течение 90 мин. Для пропитки брали навески угля-сырца разных фракций массой 10 г, высушивали в сушильном шкафу до постоянной массы и пропитывали раствором нефтебитума соответствующей концентрации 90 мин при температуре $20{ }^{\circ} \mathrm{C}$. После чего образцы выкладывали на фильтровальную бумагу и сушили на воздухе, далее досушивали в сушильном шкафу до постоянной массы.

После сушки общее количество каждого образца делилось на две равные весовые части, одна часть нагревалась в реакторе до температуры $810^{\circ} \mathrm{C}$ и подвергалась карбонизации в течение 15 мин, скорость подъема температуры до $800^{\circ} \mathrm{C}$ составляла $18^{\circ} \mathrm{C} /$ мин. Так оценивалось влияние нагрева на убыль массы угля. Вторая часть также нагревалась до температуры $810^{\circ} \mathrm{C}$ с такой же скоростью и активировалась водяным паром в течение 15 мин. Карбонизацию и активацию проводили в реакторе из нержавеющей стали, внутренний диаметр 43 мм, нагрев осуществляли электрической печью накаливания.

Адсорбционную активность по йоду полученных образцов определяли по методике, описанной в ГОСТ 6217-74, прочность на истирание - по ГОСТ 16188-70, площадь поверхности методом тепловой десорбции аргона. Погрешность определения активности по йоду, с учетом методической погрешности, устанавливалась экспериментально и составила 3,5 \% абс. при доверительной вероятности 0,95. Погрешность определения прочности на истирание составила не более 2,1 \% абс. при доверительной вероятности 0,95.

\section{Результаты и обсуждение}

В таблице 1 представлены характеристики образцов угля-сырца, полученных пиролизом экстрагированной коры лиственницы при температуре $500{ }^{\circ} \mathrm{C}$.

Обгар для соответствующих размеров зерен для исходной коры и экстрагированной коры приблизительно одинаковый. Сорбционная активность образцов угля-сырца по йоду различается незначительно за исключением образцов с размером зерна 2-3 мм. В этом случае для угля из исходной коры активность составляет $29 \%$, для угля из экстрагированной коры -36 \%. При этом удельная поверхность по БЭТ для образцов угля из исходной коры 
Таблица 1. Характеристики угля-сырца, полученного из экстрагированной коры лиственницы

\begin{tabular}{|l|c|c|c|c|c|c|}
\hline \multirow{2}{*}{\multicolumn{1}{|c|}{ Характеристики угля-сырца }} & \multicolumn{3}{|c|}{ Исходная кора } & \multicolumn{3}{c|}{ Экстрагированная кора } \\
\cline { 2 - 8 } & $2-3$ мм & $3-5$ мм & $5-6$ мм & $2-3$ мм & $3-5$ мм & $5-6$ мм \\
\hline Выход угля сырца, \% мас. & 33 & 38 & 39 & 35 & 35 & 38 \\
\hline Обгар, \% мас. & 67 & 62 & 61 & 65 & 65 & 62 \\
\hline $\begin{array}{l}\text { Адсорбционная активность } \\
\text { по йоду, \% }\end{array}$ & 29 & 28 & 20 & 36 & 31 & 22 \\
\hline Удельная поверхность, м²/г & 379 & 443 & 450 & 452 & 551 & 580 \\
\hline
\end{tabular}

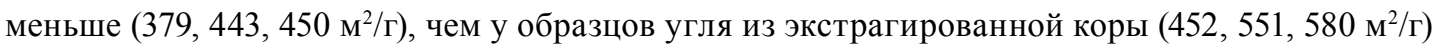
для классов крупности 2-3, 3-5, 5-6 мм соответственно. Этот факт можно объяснить тем, что в результате экстракции происходит раскрытие внутренней пористой структуры зерна коры. Интересно отметить, что удельная поверхность по БЭТ для более крупных частиц угля больше, чем удельная поверхность для частиц более мелкой фракции, и составляет $580 \mathrm{M}^{2} / \Gamma$ для фракции 5-6 мм и 452 м²/г для фракции 2-3 мм для угля из экстрагированной коры. Для угля из исходной коры поверхность по БЭТ фракции 5-6 мм равняется 450 м²/г и для фракции 2-3 мм - $379 \mathrm{~m}^{2} / \Gamma$.

Для всех образцов угля-сырца - как из исходной коры, так и из экстрагированной - величины обгара для мелких фракций 2-3 мм больше, чем величины обгара для крупных фракций 5-6 мм. Для исходной коры величина обгара фракции 2-3 мм составляет 67 \% мас., а величина обгара фракции 5-6 мм - 61 \% мас. Для угля из экстрагированной коры величина обгара фракции 2-3 мм равна 65 \% мас., а величина обгара фракции 5-6 мм - 62 \% мас. Это может быть вызвано тем, что во время пиролиза проходит также частичная газификация коры в результате ее взаимодействия с летучими веществами. Поскольку общая площадь внешней поверхности для фракций 2-3 мм больше, чем общая площадь поверхности частиц крупностью 5-6 мм, мелкая фракция газифицируется более интенсивно и общий обгар для нее становится больше, чем для фракции 5-6 мм.

Далее полученный уголь-сырец из исходной коры и экстрагированной коры пропитывали растворами нефтебитума в толуоле. Результаты пропитки угля-сырца нефтебитумом разной концентрации представлены в табл. 2.

Данные табл. 2, показывают, что при увеличении размера зерна угля-сырца происходит уменьшение количества поглощенного битума для всех представленных в таблице концентраций.

Для пылевидной фракции угля при увеличении концентрации битума происходит резкое увеличение поглощенного битума начиная с 20 \% мас. Это объясняется тем, что значительная часть битума остается на поверхности частиц угля и после сушки битум склеивает уголь в плотные «лепешки» разной прочности. Для концентраций битума 40 и 50 \% мас. склеивание происходило для всех фракций. Таким образом, часть битума оставалась на поверхности зерен и приводила к склеиванию частиц угля.

Для зерненных образцов угля по мере увеличения концентрации битума в растворе толуола с 10 до 20 \% мас. происходит увеличение массы поглощенного битума для всех фракций.

$$
-247-
$$


Таблица 2. Увеличение массы угля-сырца после пропитки раствором нефтебитума

\begin{tabular}{|c|c|c|c|c|}
\hline \multirow{2}{*}{$\begin{array}{c}\text { Концентрация битума в растворе толуола, } \\
\text { \% мас. }\end{array}$} & \multicolumn{4}{|c|}{ Увеличение массы угля после пропитки, \% мас. } \\
\cline { 2 - 5 } & \multicolumn{5}{|c|}{ фракция, мм } \\
\cline { 2 - 5 } & $0-0,1$ & $2-3$ & $3-5$ & 12 \\
\hline 10 & 44 & 25 & 14 & 29 \\
\hline 20 & 153 & 60 & 33 & 26 \\
\hline 30 & 191 & 57 & 51 & 45 \\
\hline 40 & 210 & 70 & 72 & 53 \\
\hline 50 & 220 & 80 & 70 & 12 \\
\hline
\end{tabular}

Однако при увеличении концентрации пропитывающего раствора с 20 до 30 \% мас. количество поглощенного битума остается приблизительно одинаковым, в пределах ошибки эксперимента. Это обусловлено, вероятно, тем, что объем заполненного растворителем внутреннего пространства угольных частиц в случае $30 \%$-ной концентрации меньше, чем в случае $20 \%$-ного растворителя, вследствие более высокой вязкости $30 \%$-ного раствора битума.

После пропитки нефтебитумом и сушки образцы угля подвергались термической обработке. В таблице 3 представлены данные по обгару при термической обработке угля-сырца, пропитанного растворами нефтебитума разной концентрации. Для сравнения также приведены данные для непропитанного угля-сырца (строка с концентрацией нефтебитума равной нулю). Время активации водяным паром для непропитанного угля-сырца составляло 30 мин, а для пропитанных углей - 10 мин.

Обгар не пропитанного битумом угля-сырца равнялся в среднем $22 \%$ мас. Величины обгара пропитанных битумом углей для всех фракций коры больше величин обгара непропитанного угля, и они возрастают по мере увеличения концентрации раствора. Полный обгар частиц - комбинация обгаров собственно частиц угля и обгара битума. Поскольку процессы пиролиза внутри частицы сложны, то конечный обгар нельзя представить просто как сумму обгара угольной частицы и обгара битума, эта зависимость будет более сложной. В данном случае можно лишь сказать, что часть битума при пиролизе осталась внутри угольной частицы в виде углерода.

После активации угля водяным паром величины обгаров всех образцов угля приблизительно одинаковы.

Максимальной сорбционной активностью по йоду обладает непропитанный активированный уголь - 88-75 \%. Хорошую активностью по йоду показал уголь, пропитанный $10 \%$-ным раствором битума (73 и $67 \%$ соответственно для фракций фракции 2-3 и 3-5 мм), и уголь, пропитанный раствором битума 20\%-ным (64 \% для фракции 2-3 мм). По этому показателю они превышают значение $60 \%$, установленное ГОСТ 6217 - 74 для активных углей марки БАУ. Уголь, пропитанный $30 \%$-ным раствором битума, имеет низкие значения сорбционной активности. Вероятно, при пиролизе битума часть исходных пор блокируется углеродом.

Прочность активных углей на истирание определяли по ГОСТ 16188 - 70. Предварительно для сравнения была определена прочность на истирание угля марки БАУ-А, которая составила $87 \%$. 
Таблица 3. Данные по термообработке угля-сырца, пропитанного битумом

\begin{tabular}{|c|c|c|c|}
\hline \multirow{2}{*}{$\begin{array}{c}\text { Концентрация битума в } \\
\text { растворе толуола }\end{array}$} & \multicolumn{3}{|c|}{ Уголь-сырец, пропитанный нефтебитумом } \\
\hline & \multicolumn{3}{|c|}{ Фракция угля-сырца, мм } \\
\hline \multirow{2}{*}{$\%$ мас. } & $2-3$ & $3-5$ & $5-6$ \\
\hline & \multicolumn{3}{|c|}{ Обгар угля после пиролиза при $810^{\circ} \mathrm{C}, \%$ мас. } \\
\hline 0 & 20 & 23 & 22 \\
\hline 10 & 29 & 26 & 27 \\
\hline 20 & 35 & 28 & 28 \\
\hline \multirow[t]{2}{*}{30} & 38 & 34 & 35 \\
\hline & \multicolumn{3}{|c|}{ Обгар угля после активации водяным паром при 810 C, \% мас. } \\
\hline 0 & 56 & 57 & 55 \\
\hline 10 & 52 & 52 & 42 \\
\hline 20 & 57 & 58 & 53 \\
\hline \multirow[t]{2}{*}{30} & 58 & 58 & 55 \\
\hline & \multicolumn{3}{|c|}{ Активность по йоду после активации водяным паром при 810 $\mathrm{C}, \%$} \\
\hline 0 & 88 & 82 & 75 \\
\hline 10 & 73 & 67 & 39 \\
\hline 20 & 64 & 56 & 30 \\
\hline 30 & 30 & 28 & 40 \\
\hline
\end{tabular}

Таблица 4. Прочность на истирание древесных углей после парогазовой активации при $810^{\circ} \mathrm{C}$

\begin{tabular}{|l|c|c|c|}
\hline \multirow{2}{*}{ Исходные образцы углей } & \multicolumn{3}{|c|}{ Прочность на истирание по ГОСТ 16188-70, \% } \\
\cline { 2 - 4 } & \multicolumn{3}{|c|}{ фракция, мм } \\
\cline { 2 - 4 } & $2-3$ & $3-5$ & $5-6$ \\
\hline Уголь-сырец & $80 \pm 1,5$ & $81 \pm 1,6$ & $81 \pm 1,5$ \\
& $\left(88 \%{ }^{*}\right)$ & $(82 \%)$ & $91 \pm 1,8$ \\
\hline Уголь, пропитанный 10\%-ным раствором & $90 \pm 1,7$ & $91 \pm 1,8$ & $(39 \%)$ \\
нефтебитума & $(73 \%)$ & $(67 \%)$ & $93 \pm 1,8$ \\
\hline Уголь, пропитанный 20\%-ным раствором & $92 \pm 1,7$ & $95 \pm 2,1$ & $(30 \%)$ \\
нефтебитума & $(64 \%)$ & $(56 \%)$ & $94 \pm 2$ \\
\hline Уголь, пропитанный 30\%-ным раствором & $91 \pm 2$ & $93 \pm 2,1$ & $(40 \%)$ \\
нефтебитума & $(30 \%)$ & $(28 \%)$ & $(2,8)$ \\
\hline
\end{tabular}

*- Сорбционная активность угля по йоду, \% (приведена для удобства сравнения).

Данные по прочности активных углей приведены в табл. 4.

Неактивированный уголь-сырец имеет прочность 95-97 \%. После его парогазовой активации прочность снижается до 81 \%, но при этом значительно увеличивается адсорбционная активность по йоду - до 88 \%. Добавление битума приводит к увеличению прочности, однако активность образцов по йоду при этом снижается антибатно увеличению концентрации битума в пропитывающем растворе (табл. 3). Наилучшее соотношение адсорбционная активность/ прочность достигается при пропитке угля-сырца раствором нефтебитума концентрации 10 \%.

$$
\text { - } 249 \text { - }
$$


Для фракций 2-3 и 3-5 мм адсорбционная активность по йоду составляет 73 и 67 \%, а прочность - 90 и $91 \%$ соответственно.

\section{Заключение}

Исследовано влияние нефтебитумных добавок различных концентраций к образцам угля-сырца, полученных пиролизом экстрагированной коры лиственницы, на свойства активированного угля. Установлено, что пропитка угля-сырца из экстрагированной коры лиственницы раствором нефтебитума в толуоле перед парогазовой активацией приводит к увеличению прочности на истирание активированных углей, но ухудшает их сорбционные характеристики.

Наиболее высокие показатели сорбционной активности по йоду (73 и 67 \%) и прочности на истирание (90 и $91 \%$ ) достигнуты при пропитке 10\%-ным раствором битума в толуоле фракций угля-сырца 2-3 и 3-5 мм.

\section{Список литературы}

1. Кузнецов Б.Н., Левданский В.А., Кузнецова С.А. Химические продукты из древесной коры: монография. Красноярск: Сиб. фед. ун-т, 2012. 260 с. [Kuznetsov B. N., Levdanskiy V.A., Kuznetsova S.A. Chemical products of woody-crust: monograph. Krasnoyarsk: Siberian Federal University, 2012. -260 p. (In Russ.)]

2. Кузнецов Б.Н., Чесноков Н.В., Иванов И.П., Кузнецова С.А., Иванченко Н.М. Получение пористых углеродных материалов из древесной коры. Химия твердого топлива. 2015. № 5. C. 14-24. [Kuznetsov B.N., Chesnokov N.V., Ivanov I.P., Kuznetsova S.A., Ivanchenko N.M. Preparation of porous carbon materials from the bark. Solid Fuel Chemistry. 2015. № 5. C. 14-24. (In Russ.)]

3. Кузнецов Б.Н., Головин Ю.Г., Головина В.В., Еремина А.О., Левданский В.А. Получение углеродных адсорбентов из продуктов экстракционной переработки коры лиственницы сибирской. Химия растительного сырья. 2002. №2. С. 57-61. [ Kuznetsov B.N., Golovin Yu.G., Golovina V.V., Eremina A.O., Levdanskiy V.A. Preparation of carbon adsorbents from the products extraction processing Siberian larch bark. Chemistry of plant raw materials. 2002. №2. P. 57-61. (In Russ.)]

4. ГОСТ 6217-74. Уголь активный древесный дробленый. Технические условия. 8 c. [GOST 6217-74. Coal active charcoal crushed. Technical conditions. 8 P. (In Russ.)]

5. Мазурова Е.В., Чупрова Н.А., Петров В.С., Епифанцева Н.С. Угли из пихты с нефтебитумной добавкой. Химия растительного сырья. 2002. № 2. С. 153-154. [Mazurova E.V., Chuprova N.A., Petrov V.S., Epifantseva N.S. Fir charcoal with oil bituminous additive. Chemistry of plant raw materials. 2002. № 2. P. 153-154. (In Russ.)]

6. Патент 2124562 РФ. Способ переработки коры лиственницы сибирской. Левданский В.А., Полежаева Н.И., Еськин А.П., Кузнецов Б.Н. Бюл. 1999. №1. [ Patent 2124562 RU. Levdanskii V.A., Polezhaeva N.I., Eskin A.P., Kuznetsov B.N. Method for processing the bark of Siberian larch. Bul. 1999. №1. (In Russ.)]

7. Патент РФ №2175668. Способ получения дубильного экстракта из коры лиственницы. Левданский В.А., Полежаева Н.И., Макиевская А.И., Кузнецов Б.Н. Бюл. 2001. №31. [Patent 2175668 RU. Levdanskii V.A., Polezhaeva N.I., Makievskaya A.I., Kuznetsov B.N. A method for producing tanning extract from the larch bark. Bul. 2001. №31. (In Russ.)] 
8. Иванова Н.В., Попова О.В., Бабкин В.А. Изучение влияния различных факторов на выход и некоторые характеристики пектиновых веществ коры лиственницы. Химия растительного сырья. 2003. № 4 . С. 43-46. [Ivanova N.V., Popova O.V., Babkin V.A. The study of the influence of various factors on the yield and some characteristics of pectin larch bark. Chemistry of plant raw materials. 2003. № 4. P. 43-46. (In Russ.)]

9. Оболенская А. В., Ельницкая 3. П., Леонович А. А. Лабораторные работы по химии древесины и целлюлозы: учеб. пособие для вузов. М.: Экология, 1991. 320 с. [Obolenskaya A.V., Elnitskaya Z.P., Leonovich A.A. Laboratory works on wood and cellulose chemistry: Textbook for high schools. M.: Ecology, 1991. 320 P. (In Russ.)] 